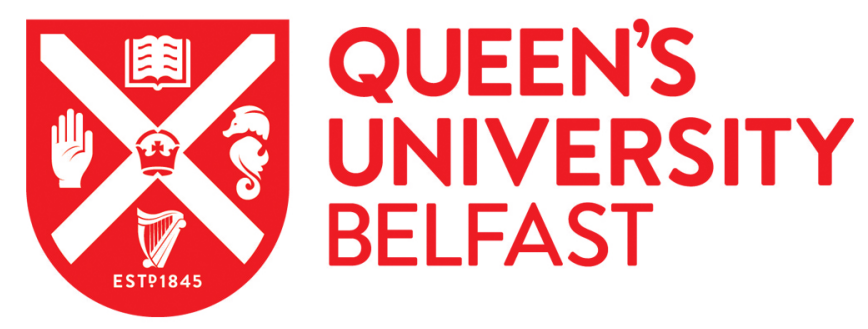

\title{
Walking on sunshine: scoping review of the evidence for walking and mental health
}

Kelly, P., Williamson, C., Niven, A., Hunter, R., Mutrie, N., \& Richards, J. (2018). Walking on sunshine: scoping review of the evidence for walking and mental health. British Journal of Sports Medicine, 52(12), 800-806. https://doi.org/10.1136/bjsports-2017-098827

Published in:

British Journal of Sports Medicine

Document Version:

Peer reviewed version

Queen's University Belfast - Research Portal:

Link to publication record in Queen's University Belfast Research Portal

Publisher rights

Copyright 2018 BMJ. This work is made available online in accordance with the publisher's policies. Please refer to any applicable terms of use of the publisher.

\section{General rights}

Copyright for the publications made accessible via the Queen's University Belfast Research Portal is retained by the author(s) and / or other copyright owners and it is a condition of accessing these publications that users recognise and abide by the legal requirements associated with these rights.

Take down policy

The Research Portal is Queen's institutional repository that provides access to Queen's research output. Every effort has been made to ensure that content in the Research Portal does not infringe any person's rights, or applicable UK laws. If you discover content in the Research Portal that you believe breaches copyright or violates any law, please contact openaccess@qub.ac.uk. 


\section{TITLE}

2 Walking on sunshine: scoping review of the evidence for walking and mental health 3

4 AUTHOR AND AFFILIATIONS:

5 Paul Kelly ${ }^{1}$, Chloë Williamson ${ }^{1}$, Ruth Hunter $^{2}$, Ailsa Niven ${ }^{1}$, Nanette Mutrie ${ }^{1}$, Justin Rich$6 \operatorname{ards}^{3}$

7

$8 \quad{ }^{1}$ Physical Activity for Health Research Centre, Institute for Sport, Physical Education and

9 Health Sciences, University of Edinburgh, UK

$10 \quad{ }^{2}$ Queen's University Belfast, Belfast, UK

$11{ }^{3}$ Charles Perkins Centre \& School of Public Health, University of Sydney, Australia

CORRESPONDING AUTHOR

14 Paul Kelly, Physical Activity for Health Research Centre, Institute for Sport, Physical

15 Education and Health Sciences, University of Edinburgh, UK

email: p.kelly@ed.ac.uk T: +44(0)1416514111

Word Count

Abstract: 221

Main Text: 4286 


\section{ABSTRACT}

2 Background/Objectives: Walking has well established positive relationships with, and

3 effects on, physical health. In contrast, while poor mental health contributes substantially to

4 global health burden, an overview of the benefits from walking has not previously been

5 published. We aimed to scope the literature and present what is known, and highlight what is

6 not known, about walking and mental health.

7 Methods:

8 Design: Scoping review

9 Data sources: Ovid (Medline), ProQuest, Web of Science

10 Screening and reporting: 13,014 records were identified and screened by a team of

11 researchers. Included full texts were analysed and reported according to mental health

12 outcome.

13 Results: For the 8 mental health outcomes (identified a priori) there were a total of 5

14 systematic reviews and 50 individual papers included. Depression had the most evidence and

15 existing systematic reviews were reported. Evidence for anxiety, psychological stress,

16 psychological well-being, subjective well-being and social isolation and loneliness varied in

17 volume and effectiveness, but no harmful effects were identified. There were no studies for

18 walking and resilience. The setting and context of walking seems to be important variables.

19 Conclusion: The evidence base that suggests walking benefits mental health is growing, but

20 remains fragmented and incomplete for some important outcomes. Policy and national guide-

21 lines should promote the known mental health benefits of increased walking and future re-

22 search should directly address the gaps we have identified.

\section{Keywords}

24 Walking, physical activity, mental health 


\section{What are the new findings?}

- Over the last 20 years the evidence base for the beneficial effects of walking for mental health has grown, but remains fragmented and incomplete for some important outcomes;

- For depression and anxiety there may be sufficient evidence to promote walking to prevent and treat these conditions;

- There has been more research on the negative disease based outcomes (such as depression and anxiety) than for the positive well-being outcomes (such as happiness or subjective well-being);

- The evidence base seems to indicate that across the mental health outcomes there are additional benefits from walking outdoors in natural environments compared to indoor, treadmill based walking. 


\section{INTRODUCTION}

2 Regular walking is known to confer many physical health benefits including better physical

3 fitness, reduction in disease risk, and reduced risk of disease specific and all-cause mortality. ${ }^{1}$

$4 \quad{ }^{2}$ In addition to physical health, mental health also contributes substantially to global health

5 burden ${ }^{3}$ and there is well established evidence for the link between physical activity and

6 several mental health outcomes. ${ }^{4}$ This includes variable levels of evidence for: Depression,

7 Anxiety, Psychological Distress, Well-Being, Cognitive Function, Dementia, Sleep, Self-

8 Esteem, Chronic Fatigue and Psychological Events. ${ }^{4}$

10 While the link between physical activity and mental health is well established, ${ }^{56}$ substantially 11 less is known about the role of walking in this respect. ${ }^{1}$ Morris and Hardman identified this gap in their seminal "Walking to Health" paper in 1997 and stated that "The pleasurable and therapeutic, psychological and social dimensions of walking, whilst evident, have been surprisingly little studied". ${ }^{7}$ Addressing this gap in knowledge is important as walking is an accessible behaviour conducted by all ages and sexes, and as such one with great public health potential. ${ }^{8}$

Consequently, the aims of this review are to:

(i) Provide an overview of what has been learned in the intervening 20 years in regard to preventing mental ill-being, promoting mental well-being and intervention effects; 


\section{METHODS}

We adopted the established five stage scoping review process proposed by Arksey and O’Malley. ${ }^{9}$

\section{Stage 1.1: Identify the research question}

We formulated the following research question: "What is known about the associations and

effects of walking when considering various specified mental health outcomes?"

For the purposes of this review, we adopted the following definition of walking which we have used previously: walking was taken to mean all forms of purposeful or incidental bipedal locomotion within reasonable speed ranges (i.e. not running or jogging). ${ }^{1}$

\section{Stage 1.2: Identify the relevant outcomes}

The review team discussed each mental health outcome identified in the 2008 Physical Activity Guidelines Advisory Committee Report for relevance, appropriateness, and feasibility for this study. ${ }^{4}$ Two authors were Chartered Psychologists registered with the British Psychological Society and provided expert opinion in this process (NM, AN). Depression [Outcome 1 (O1)], Anxiety [O2], Self-Esteem [O3] were retained. Psychological Distress was classified under Psychological Stress [O4]. Well-Being was split into Psychological Well-Being [O5] and Subjective Well-Being [O6] due to established evidence for the differences between these eudemonic and hedonic constructs. ${ }^{1011}$ Resilience [O7] and Social Isolation and Loneliness [O8] were added as areas of particular mental health and public health interest. The outcomes were given operational definitions as shown in Table 1. 
Table 1. Mental health outcomes included in this review

\begin{tabular}{|c|c|c|}
\hline & Outcome & Description \\
\hline 1 & Depression & $\begin{array}{l}\text { Depression is a mood disorder categorised by prolonged periods of low mood, or } \\
\text { lack of interest and/or pleasure in normal activities most of the time. Depression } \\
\text { includes Dysthymia and Major Depressive Disorder. }{ }^{12}\end{array}$ \\
\hline 2 & Anxiety & $\begin{array}{l}\text { Anxiety is characterised by uncomfortable or upsetting thoughts, and is usually ac- } \\
\text { companied by agitation, feelings of tension, and activation of the autonomic nervous } \\
\text { system. It is important to note the distinction between transient anxiety symptoms } \\
\text { (state anxiety), persistent symptoms (trait anxiety), and anxiety disorders: a collec- } \\
\text { tion of disabling conditions characterised by excessive, chronic anxiety. Examples of } \\
\text { anxiety disorders are: specific phobias, social phobia, generalised anxiety disorder, } \\
\text { panic disorder, obsessive-compulsive disorder, and post-traumatic stress disorder. }\end{array}$ \\
\hline 3 & Self-esteem & $\begin{array}{l}\text { Self-esteem is the feelings of value and worth that a person has for oneself. It con- } \\
\text { tributes to overall self-concept as a construct of mental health. }{ }^{13}\end{array}$ \\
\hline 4 & $\begin{array}{r}\text { Psychological } \\
\text { stress }\end{array}$ & $\begin{array}{l}\text { Psychological stress or distress can be defined as the unique discomforting, emotion- } \\
\text { al state experienced by an individual in response to a specific stressor or demand that } \\
\text { results in harm, either temporary or permanent, to that person. }{ }^{14}\end{array}$ \\
\hline 5 & $\begin{array}{r}\text { Psychological } \\
\text { well-being }\end{array}$ & $\begin{array}{l}\text { Psychological well-being links with autonomy, environmental mastery, personal } \\
\text { growth, positive relations with others, purpose in life, and self-acceptance. This is } \\
\text { often referred to as eudemonic well-being. }{ }^{10}\end{array}$ \\
\hline 6 & $\begin{array}{r}\text { Subjective well- } \\
\text { being }\end{array}$ & $\begin{array}{l}\text { Subjective well-being is defined as a person's cognitive and affective evaluations of } \\
\text { his or her life. Often referred to as hedonic well-being (and closely aligned with the } \\
\text { construct of happiness). }{ }^{11}\end{array}$ \\
\hline 7 & Resilience & $\begin{array}{l}\text { Resilience refers to a steady trajectory of healthy functioning after a highly adverse } \\
\text { event, or a conscious effort to continue in an insightful and integrated positive man- } \\
\text { ner as a result of lessons learned from an adverse experience. }{ }^{15}\end{array}$ \\
\hline 8 & $\begin{array}{r}\text { Social isolation } \\
\text { and loneliness }\end{array}$ & $\begin{array}{l}\text { Social isolation is described as lack of a social network while loneliness is described } \\
\text { as an unfulfilled social need. }{ }^{16}\end{array}$ \\
\hline
\end{tabular}

6 From the original list Dementia was classified under Cognitive Dysfunction (including Alz-

7 heimer's and Parkinson's). These were considered neurological health rather than mental

8 health ${ }^{3}$ and were not deemed within the scope of this review. Sleep, Chronic Fatigue and

9 Psychological Events were considered important but outside the scope and feasibility of this review. Health Related Quality of Life (HRQoL) was discussed extensively, but ultimately 


\section{Stage 2: Identifying relevant studies}

5 Studies were included if they met the following inclusion criteria:

6 to what we have captured in subjective and psychological well-being. ${ }^{17}$

- Research articles in any geographical location or setting

- Published in English in peer-reviewed academic journals

o Preventive effects (deleterious outcomes)

o Health promotion effects (positive outcomes)

o Intervention effects (all outcomes) search studies

- Include any age groups or sex

Studies were excluded based on the following exclusion criteria: health (e.g. effects on depression in stroke patients) dissertations and conference proceedings

- Qualitative and ethnographic designs

as it is considered a comparatively transient state that cumulatively contributes more broadly

- Specify quantitative effects of walking on the predetermined mental health outcomes

- Designs including: primary research studies (cross-sectional or longitudinal designs, interventions or natural experiments with pre-post measures and a comparison), reviews, systematic reviews, scoping reviews, and meta-analyses of suitable primary re-

- Focus only on clinical groups with a specific physical or mental illness or condition that is not the illness or condition being treated with walking i.e. secondary mental

- Evidence types including: guidelines, unpublished and ongoing trials, annual reports, 
3 In studies of participants aged less than 18 years, pedometers were not considered measures

4 of walking exposure due to the likely large proportion of counts from other common forms of

5 physical activity (e.g. unstructured and structured play, and sporadic movement), but we did

6 retain this as a measurement method in adults for whom pedometer counts are more likely to 7 reflect walking.

8

\section{$9 \quad$ Search strategy and databases}

- Editorials, opinion pieces, magazine and newspaper articles, case reports, papers with no primary data

The strategy was designed to be as comprehensive as possible, within the constraints of time and resource. ${ }^{9}$ We used the outcomes in Table 1 to define search terms that were adapted for each relevant electronic database and combined with common walking terms. Search terms and databases are shown in Supplementary Table S1. Searches were conducted in October 2017.

\section{Stage 3: Study selection}

All identified records were uploaded to the online Covidence software

(https://www.covidence.org). Duplicates were automatically removed. Titles and abstracts were reviewed by 2 researchers (PK, CW) with $20 \%$ cross-checked early in the process to assess agreement. Full texts were reviewed independently by 2 researchers (PK, section lead) with conflicts resolved by a third author.

Scoping reviews are known to be iterative in nature as the researchers become more familiar with the data. ${ }^{9}$ In this review it became apparent that O1: Depression had a more mature evi- 
1 dence base, characterised by many studies and a number of systematic reviews. We therefore

2 changed our methods and criteria to include only existing reviews for this outcome.

\section{$4 \quad$ Stage 4: Charting the data}

5 For each outcome, key information from the relevant included texts was extracted into a

6 standard data form (modified for the depression systematic reviews). Information included:

7 author, year, location, design, sample size and characteristics, exposure or intervention char-

8 acteristics, comparator or control characteristics, outcome measures and key findings.

9

10

\section{Stage 5: Collating, summarising and reporting the results}

The analytic framework for collating the data was the 8 mental health outcomes (see Table 1). The aim was to report relevant information on the volume, nature, distribution and characteristics of published studies. We utilised the 'descriptive-analytical' method from the narrative tradition, which involves applying a common analytical framework to all the primary research reports and collecting standard information on each study. ${ }^{9}$ Narrative summaries for each outcome as well as key concepts and related research gaps were reported. 


\section{RESULTS}

2 In total, we identified 13,014 records from database searches. For depression we included 5

3 systematic reviews, while for resilience there were no included studies. Across the 6 other

4 outcomes, there were 50 included papers (see Figure 1) though some studies appeared in

5 more than one outcome. The findings for each outcome are reported below, with further

6 descriptive information in Supplementary table S2.

7

\section{Outcome 1: Depression}

9 Of the outcomes in this review, depression has the most developed evidence base. Specifical10 ly, we report five systematic reviews. ${ }^{18-22}$ There were no reviews of walking and prevention 11 of depression, but a 2013 systematic review of physical activity and the prevention of depression included three prospective studies of walking and all found a protective effect. ${ }^{23-25}$ Further studies that distinguish whether there are differential effects for demographics such as age and gender/sex are needed.

Considering treatment, Robertson et al (2012) concluded from 8 eligible randomised controlled trials (RCT) that walking was an effective intervention for clinical depression with an effect size of $-0.86 .{ }^{19}$ This can be considered a large effect and is at least comparable to effect sizes found in systematic reviews of exercise interventions for depression. ${ }^{26}$ This finding strongly supports the use of walking as a treatment for depression, and yet more needs to be known since 8 studies in this review remain a relatively small evidence base when considering representation of all ages, genders and other relevant demographics.

24 A systematic review focussed on walking group interventions concluded they were effective

25 for reducing depression scores. ${ }^{20}$ However, these findings should be interpreted cautiously as 
1 it was not clear if depression was clinically defined and study design was not limited to ran-

2 domised controlled trials. A further recent systematic review and meta-analysis looked at the

3 effects of physical activity on post-natal depression (PND) and weight-loss. ${ }^{21}$ Four of the nine

4 included studies were walking or pram-walking (with a $5^{\text {th }}$ including walking) but effects on

$5 \quad$ PND were no better than comparison groups.

6

7 A 2013 systematic review examined modes and settings in effective physical activity inter-

8 ventions to treat depression, identifying 5 eligible RCTs. ${ }^{22}$ The authors concluded that indoor

9 or outdoor walking was a beneficial aerobic exercise to treat depression. They recommended at least some supervision, performed three to four times weekly at a moderate or self-selected intensity for 30-40 min over a period of at least nine weeks.

\section{Outcome 2: Anxiety}

14 We identified 14 studies focusing on associations between walking and anxiety. ${ }^{27-40}$ After 15 depression this was the second biggest evidence base. Of five cross-sectional studies, four showed an association between walking and lower anxiety scores ${ }^{27-30}$ while one did not ${ }^{32}$. Heesch et al., (2012) also found dose-response associations in prospective models. ${ }^{30}$

Four studies investigated the acute effects of walking on anxiety and found mixed effects. ${ }^{35-}$ ${ }^{37}$ Five studies compared walking interventions to a comparison condition over time (6-12 weeks) and found favourable treatment effects. 3133343839

23 Overall, walking appears to be beneficial for anxiety. Despite our attempts to operationalise 24 the meaning of "anxiety" a priori this remains a broad construct, which made it difficult to draw over-all conclusions. Given the magnitude of the global burden of anxiety this may be 
1 sufficient rationale for more focussed study of walking and anxiety. There is a clear need to

2 develop more prospective epidemiology that could assess both walking and persistent symp-

3 toms of anxiety and or clinically defined anxiety disorders.

\section{Outcome 3: Self-esteem}

6 We identified 11 studies that examined the association between walking and global self-

7 esteem (GSE). ${ }^{3641-50}$ There were two cross-sectional studies that examined the relationship

8 between walking and GSE. ${ }^{42} 43$ Both reported no association. We found no prospective anal-

9 yses. Two acute studies reported benefit on GSE following a single bout of walking. ${ }^{36} 44$

11 There were seven intervention studies that compared walking condition(s) with another con12 dition over time (8-12 weeks) with both favourable and null effect findings. ${ }^{41}{ }^{45-50}$ Walking programmes varied in length from eight weeks to 12 months, and in frequency, duration, intensity, and progression of dose. Two studies suggested significant improvement in GSE following walking compared with comparator groups. Three of the studies suggested significant improvement in GSE following walking, but this was no greater than the comparator, and two studies showed no change in GSE.

Overall, the evidence suggests that walking interventions have a positive effect on selfesteem, but observational findings were limited. Whilst not a focus of this review, several of the included studies also incorporated other measures of self-perception (e.g., physical selfworth) that contemporary theoretical perspectives of 'self' would suggest are more susceptible to change following walking than GSE, and particularly in acute studies. ${ }^{51}$

\section{Outcome 4: Psychological stress}


1 We identified six studies that examined the relationship between walking and psychological

2 stress. $^{32}{ }^{37} 52-55$ One cross-sectional study showed a large significant association ${ }^{32}$ and another

3 showed a small non-significant association ${ }^{32}$. Threes studies assessed the acute effects of

$4 \quad$ walking on psychological stress 553754 and findings were contradictory. One four week long

5 intervention showed promising effects at intervention completion but had no effect at 12

6 week follow-up. ${ }^{53}$

7

8 In summary, there is emerging but limited evidence that walking is associated with lower

9 psychological stress in observational studies, and that can be used as a potentially promising

10 intervention to decrease psychological stress. It is however clear that available evidence is not 11 yet sufficient for firm conclusions.

\section{Outcome 5: Psychological well-being}

14 We identified 11 studies that examined the association between walking and psychological well-being (PWB). ${ }^{32} 34$ 56-59,60-64 There were three cross-sectional studies that examined the association between walking and PWB. The findings generally supported a positive association between PWB and walking. ${ }^{62} 3260$ One large scale longitudinal study showed positive findings for walking for transport.$^{63}$ There were no acute studies.

Seven RCT studies compared the effects of walking interventions on PWB with another condition (typically minimal intervention) over 10-15 weeks. The findings were mixed with instances of no improvements, no between group effects, and some positive effects for walking. ${ }^{34}$ 56-59 6164 A targeted review to understand the differential effects of intervention design and/or study quality may be required. 
1 To conclude, the evidence is limited but promising with cross-sectional studies and the one

2 longitudinal study identifying positive relationships between walking and PWB. The find-

3 ings from the intervention studies are more mixed with only two of seven studies demonstrat-

4 ing positive effects on PWB compared to control groups.

5

\section{Outcome 6: Subjective well-being}

7 We identified twelve studies focusing on associations between walking and subjective well-

8 being (SWB). ${ }^{32} 364065-73$ There was diversity in how SWB was described and measured in the

9 identified papers including life satisfaction, happiness, emotional well-being and affective

10 response. From four cross-sectional studies, three found significant associations between

11 higher levels of walking and better SWB 32656669 Two prospective cohort studies found weak

12 but statistically significant relationships between walking and subsequent SWB. ${ }^{70} 68$

14 Five studies found positive acute effects for a single bout of walking on indicators of SWB. ${ }^{36}$ 40 71-73 One intervention compared walking to stretching and toning over 6 months and found equivalent improvements in "happiness" and "life satisfaction" in both groups. ${ }^{67}$

In summary, cross-sectional, prospective cohort and acute studies indicate an association between walking and SWB. The only long-term intervention study was inconclusive and further studies are clearly required.

Outcome 7: Resilience

23 The relationship between physical activity and resilience is emerging ${ }^{74}$ with associations

24 shown in undergraduate students ${ }^{74}$ and healthy adults. ${ }^{75}$ However, we identified no published 25 journal articles addressing the association specifically between walking and resilience. 
2 Outcome 8: Social isolation and loneliness

3 The topic of "social health" is broad, and for the purposes of this scoping review we have

4 restricted the focus to social isolation and loneliness given their direct impact on mental

5 health. ${ }^{76}$ We identified five studies. ${ }^{67}{ }^{77-80}$ A cross-sectional study found significant positive

6 associations for frequency of contacts with neighbours, neighbours' social support, neigh-

7 bourhood involvement and participation, and walking behaviour. ${ }^{77}$ However, four interven-

8 tion studies showed mixed evidence. ${ }^{78} 798067$

10 As noted previously, ${ }^{76}{ }^{81}$ the social environment is complex and lacks consensus regarding 11 definitions of core constructs, which we believe has limited this scoping review. In line with the call to action by Hunter et al (2018) in this special edition, ${ }^{76}$ further research in this area is required to: 1) create a taxonomy providing a consensus of definitions for core concepts of the social environment; 2) synthesise this complex evidence base to better guide the development of theory and conceptual models for walking behaviour and mental health; 3 ) develop interventions that utilise walking to promote social interactions to enrich existing social networks, or help create new social networks.

\section{Summary of key findings for mental health outcomes}

20 Table 2 summarizes the state of the evidence for walking and the 8 mental health outcomes

21 included in this study. Depression and anxiety are the two outcomes with consistent evidence for beneficial effects. Self-esteem, PWB, SWB and psychological stress have either limited or mixed findings for prevention and treatment. We found no studies investigating resilience.

24 Social isolation and loneliness remains a particularly complex area requiring further concep- 
1 tual mapping. The volume and distribution of study type suggests that there is a particular

2 evidence gap for prospective designs (see Figure 2).

3

4 Table 2. Summary of key findings for mental health outcomes

\begin{tabular}{|c|c|c|}
\hline & Outcome & Key findings \\
\hline 1 & Depression & Systematic review level evidence for prevention and treatment \\
\hline 2 & Anxiety & Multiple studies showing preventive and treatment effects \\
\hline 3 & Self-esteem & $\begin{array}{l}\text { No evidence for preventive effects; mixed evidence for treatment } \\
\text { effects }\end{array}$ \\
\hline 4 & Psychological stress & Limited but emerging evidence for preventive and treatment effects \\
\hline 5 & $\begin{array}{r}\text { Psychological well- } \\
\text { being }\end{array}$ & $\begin{array}{l}\text { Limited but emerging evidence for preventive effects; mixed evi- } \\
\text { dence for treatment effects }\end{array}$ \\
\hline 6 & Subjective well-being & $\begin{array}{l}\text { Emerging evidence for preventive effects and emerging but limited } \\
\text { evidence for treatment effects }\end{array}$ \\
\hline 7 & Resilience & No evidence found \\
\hline 8 & $\begin{array}{r}\text { Social isolation and } \\
\text { loneliness }\end{array}$ & $\begin{array}{l}\text { Minimal evidence found, but some promising findings; area needs } \\
\text { mapping conceptually }\end{array}$ \\
\hline
\end{tabular}

5

6 

6 findings are mixed.

7

\section{Key concepts and research gaps in the walking and mental health literature}

\section{DISCUSSION}

We aimed to scope and understand what is known about the associations and effects of walking when considering various specified mental health outcomes. To our knowledge this is the first review of the evidence of multiple mental health outcomes and walking. We have shown areas where the evidence base is well developed, and also areas where it is limited and

Having addressed the nature and sources of evidence for walking and mental health, we then mapped the key concepts in the included studies and highlighted research gaps and priorities. ${ }^{9}$ These are displayed in Figure 3, organised in five overall themes; (i) context of walking, (ii) dose of walking, (iii) study design, (iv) demographic effects, (v) conceptual framework.

\section{Context of walking}

A considerable proportion of studies compared the effect of setting or type of walking. Additional papers that did not meet the inclusion criteria included studies on types of outdoor environment, ${ }^{82}$ green environments compared to urban, ${ }^{83-85}$ forest settings, ${ }^{86}$ parks compared to woodlands, ${ }^{87}$ and green exercise that included walking. ${ }^{88}$ They suggested a multitude of positive effects on a range of mental health outcomes for green, outdoor, and natural environments, with variations by types of green settings.

A 2011 systematic review of indoor versus outdoor exercise identified 11 studies, seven of which were walking. ${ }^{89}$ Outdoor walking showed positive effects across a range of mental health outcomes compared to indoor walking, as well as increased intention for future walking. However, the authors concluded that there was still a paucity of high quality 
1 evidence. A 2010 systematic review of mental health effects of walking in natural versus

2 synthetic environments had similar findings. ${ }^{90}$ Conversely, the social context, whether

3 walking alone, with friends, partners, or in a group has not been extensively studied.

5 There was insufficient evidence to draw conclusions on purpose of walking. This issue may

6 be more critical than physiological dose for both effect and public health messaging. Very

7 few studies we identified compared, for example, commuter walking to leisure walking or

8 dog walking. Furthermore, the difference between walking by choice, or necessity, is not well

9 understood. More needs to be known about the role of context of walking, and this is a clear

10 research priority.

\section{Dose of walking}

13 Differential "dose-response" effects by frequency, duration, intensity, and length of interven14 tion or exposure time are not yet well understood. More needs to be known about the optimal 15 dose of walking to benefit different mental health outcomes and the relative importance of 16 this factor. Intensity of walking, is a particular area of interest. The differences between a 17 brisk walk, a slow shuffle, and the differential effects as fitness declines with age and relative intensity of walking increases needs to be better understood for effective public health messaging and intervention. Increasing evidence suggests physiological health effects for walking differ by intensity (Stamatakis (2018) in this special edition); it is important to understand

21 if the same is true for mental health.

23 Understanding these dose related factors will be intrinsically linked to how walking is meas24 ured. When considering intensity, self-report measures can explore perceived intensity, with25 in the limitations of recall bias, while objective measures like pedometers may be able to as- 


\section{$5 \quad$ Study design}

6 In terms of study design, there are evidence gaps around the nature and content of compari-

sess cadence. Measures of pace/speed and associated measurement of aerobic fitness or response may be required. Our scoping review found that measurement of walking varies considerably, and much learning is required in this area. son conditions, sample sizes with many small studies, and insufficiently powered analyses of mental health outcomes as secondary or tertiary outcomes. Selection and application of appropriate mental health measures is also a key concept in the literature.

\section{Demographic effects}

The effects of walking by sex, age, socioeconomic status and other important demographics remains a research priority. We are not able to say if existing evidence is generalizable across demographics. The potential interaction of demographics with dose and context of walking is another important research gap.

\section{Conceptual framework for walking and mental health}

This review highlights areas where the theory of walking and mental health could be expanded through development of an appropriate conceptual framework. The different outcomes, the complexity of the outcomes, the development of ecologically valid interventions, and understanding the mechanisms could benefit from an agreed framework.

There is comparatively less research on mental well-being (e.g. SWB, self-esteem) as opposed to mental ill-being (e.g. depression, anxiety) particularly for interventions. It is important to note that these are independent mental health constructs rather than descriptors that 
1 sit at opposite ends of the same spectrum. While the absence of depression or anxiety is clear-

2 ly desirable, it does not necessarily equate to high levels of SWB or self-esteem. This mirrors

3 the overall definition of health - not merely the absence of disease, but the presence of well-

4 being - and serves as a reminder of the holistic nature of public health in practice. It may also

5 be an important factor to consider when developing public health messaging that is targeted

6 at behaviour change. Specifically, positive messages about improving well-being through

7 walking may resonate more with segments of the population than the disease aversion mes-

8 sages that have historically pervaded the health promotion sector. Further investigation of the

9 relative contribution of walking to well-being and ill-being outcomes is indicated and should

10 also take into the account the most effective methods to influence physical activity behaviour.

12 The complexity of the mental health domain was a key theme. To quote one of the included studies "Mental health is a vast and complex domain, which reaches far beyond symptoms, disorders and diagnoses." 32 Whether studies looking at single outcomes could address this domain adequately is for discussion. The reductionist nature of examining these outcomes in isolation may not be appropriate when considering the interwoven nature of psychological constructs and the high prevalence of comorbid mental illnesses, while studies with multiple outcomes may be accused of cherry-picking favourable findings. Furthermore, despite efforts to define different mental health outcomes in the literature, there appears to be ongoing confusion and conjecture in the language to describe these constructs. This was particularly challenging when attempting to categorise studies that used varying outcome definitions.

23 To have population-level effects, there is a need to transfer promising laboratory and tread24 mill findings to ecologically valid, free-living settings. This will require the development of 25 robust programme theory to understand and evaluate delivery and impact. Similarly, the need 
2 For example, is it the physiological dose of walking that provides the effect, or is walking a

to establish and understand mechanisms of effect is an important priority for future research. vector for increased social contact and support? Or is it a combination of pathways? ${ }^{91}$ Furthermore, the interaction and relative importance of the contextual setting (e.g. forest trail vs urban street) of walking and its underlying purpose (e.g. leisure vs commute) remains unclear.

\section{Implications and future research}

Our findings suggest that while the gap identified by Morris and Hardman has seen a growth in research and evidence, it is not as developed as other areas (e.g. physiological responses, cardiovascular disease, or all cause-mortality). Nor is it as developed as we expected when we began this review. Specifically, once mental health was categorised into individual outcomes, in many cases the number of studies found was not high. There remains a vast number of questions and evidence gaps as summarised in Figure 3.

The implications for future research clearly include addressing the limited volume and quality of prospective and intervention studies for each mental health outcome. In terms of policy and practice, discussion and expert consensus is required on whether the current evidence base is sufficient to make recommendations for walking and mental health. For example, to what extent could the mental health benefits of walking be included in the upcoming update of physical activity guidelines by the UK Chief Medical Officers?

Strengths and limitations

24 The present study has a number of strengths. It is the first review of such a broad range of mental health outcomes specific to walking. It considers both prevention and intervention 
1 effects, and it identifies the volume and distribution of the evidence base. This has shown

2 where we have good evidence for walking, and where more research is warranted. We have

3 also mapped the key concepts and research priorities within the literature.

4

5 There are a number of limitations to consider. We only included quantitative studies. This

6 decision was made as qualitative designs address different questions out-with our research

7 aims. However, several qualitative studies were evident in the searches and a similar review

8 of this evidence could be highly instructive. As with any review, publication bias is an issue.

9 It is not clear how many other studies showed no effect or deleterious effects and were not 10 published.

11

12 In many studies walking was reported as physical activity or aerobic-exercise. Alternatively, strategy would have identified additional relevant studies. the exposure or intervention was walking and running/jogging or progression from walking to jogging. This excluded a large volume of literature. We did not include a number of critical outcomes such as dementia, cognitive function, mood, and HRQoL. These contribute substantially to health burden. Additionally, we did not include secondary effects in clinical populations. There is a substantial volume of literature in these populations that may need scoping in the future.

It was necessary to limit our search terms and publication language to ensure the review was feasible and focussed. It is possible we missed some important literature and a broader search

\section{Conclusions}


1 Walking is known to benefit physical health. We have shown how the evidence base for spe-

2 cific mental health outcomes and benefits has grown since Morris and Hardman's "Walking

3 to Health" review in $1997 .{ }^{7}$ In 1997 , they stated that "The pleasurable and therapeutic, psy-

4 chological and social dimensions of walking, whilst evident, have been surprisingly little

5 studied". Despite the growth in the evidence base, given the importance of mental health, and

6 the evidence gaps identified, we think this statement still holds true. We anticipate that this

7 scoping review will stimulate more research in this area.

8

9 


\section{Competing Interests}

2 There are no competing interest for any author.

3

\section{Contributorship statement}

5 PK conceived the study. PK, NM, AN, JR and CW designed the search strategy. CW

6 conducted searching of databases. PK and CW screened records. All authors contributed to

7 screening full texts. All authors led analysis and writing for at least one mental health

8 outcome. PK and CW drafted the full manuscript and all authors reviewed and approved final

9 submission.

11 Acknowledgements

12 We would like to thank Marshall Dozier, Evy Horton and Olivia Alliott for their help and 13 support.

15 Funding information

16 There is no funding to report for this submission.

Figure Legends

Figure 1. Simplified study flow chart (full PRISMA charts available from authors on request)

20 Figure 2. Distribution of studies by outcome

21 Figure 3. Key concepts and research gaps in the walking and mental health literature 
1. Kelly $P$, Murphy $M$, Mutrie N. The Health Benefits of Walking. Walking: Connecting Sustainable Transport with Health: Emerald Publishing Limited, 2017:61-79.

2. Kelly $P$, Kahlmeier S, Gotschi T, et al. Systematic review and meta-analysis of reduction in all-cause mortality from walking and cycling and shape of dose response relationship. The international journal of behavioral nutrition and physical activity 2014;11(1):132.

3. Whiteford HA, Ferrari AJ, Degenhardt L, et al. The Global Burden of Mental, Neurological and Substance Use Disorders: An Analysis from the Global Burden of Disease Study 2010. PLoS ONE 2015;10(2):e0116820.

4. Physical Activity Guidelines Advisory Committee. Physical Activity Guidelines Advisory Committee Report,. In: US Department of Health and Human Services, ed. Washington DC, 2008:A1-H14.

5. Ekkekakis $\mathrm{P}$, editor. Routledge handbook of physical activity and mental health. London: Routledge, 2013.

6. Biddle SJH, Mutrie N, Gorely T. Psychology of Physical Activity. Determinants , well being and interventions. Third ed. London: Routledge, 2015.

7. Morris JN, Hardman AE. Walking to health. Sports Medicine 1997;23(5):306-32.

8. Strain T, Fitzsimons C, Foster C, et al. Age-related comparisons by sex in the domains of aerobic physical activity for adults in Scotland. Prev Med Rep 2016;3:90-7.

9. Arksey H, O'Malley L. Scoping studies: towards a methodological framework. Int J Soc Res Methodol 2005;8(1):19-32.

10. Ryff CD. Eudaimonic well-being and health: Mapping consequences of self-realization. Washington DC: American Psychological Association, 2013.

11. Diener E, Oishi S, Lucas RE. Personality, culture, and subjective well-being: emotional and cognitive evaluations of life. Annu Rev Psychol 2003;54(1):403-25.

12. American Psychiatric Association. Diagnostic and statistical manual of mental disorders (DSM-5®): American Psychiatric Pub, 2013.

13. Pressman SD, Cohen S. Does positive affect influence health? Psychological Bulletin 2005;131(6):925.

14. Ridner SH. Psychological distress: concept analysis. J Adv Nurs 2004;45(5):536-45.

15. Southwick SM, Bonanno GA, Masten AS, et al. Resilience definitions, theory, and challenges: interdisciplinary perspectives. Eur J Psychotraumatol 2014;5(1):25338.

16. Cattan $M$, White $M$, Bond J, et al. Preventing social isolation and loneliness among older people: a systematic review of health promotion interventions. Ageing \& Society 2005;25(1):41-67.

17. Schwarz N, Clore GL. Mood, misattribution, and judgments of well-being: Informative and directive functions of affective states. Journal of Personality and Social Psychology 1983;45(3):513.

18. Mammen G, Faulkner G. Physical activity and the prevention of depression: a systematic review of prospective studies. Am J Prev Med 2013;45(5):649-57.

19. Robertson R, Robertson A, Jepson R, et al. Walking for depression or depressive symptoms: A systematic review and meta-analysis. Mental Health and Physical Activity 2012;5:66-75.

20. Hanson S, Jones $A$. Is there evidence that walking groups have health benefits? A systematic review and meta-analysis. Br J Sports Med 2015;49(11):710-5.

21. Saligheh $M$, Hackett $D$, Boyce $P$, et al. Can exercise or physical activity help improve postnatal depression and weight loss? A systematic review. Archives of Women's Mental Health 2017:1-17.

22. Stanton R, Reaburn P. Exercise and the treatment of depression: a review of the exercise program variables. Journal of Science and Medicine in Sport 2014;17(2):177-82. 
23. Lucas M, Mekary R, Pan A, et al. Relation between clinical depression risk and physical activity and time spent watching television in older women: a 10-year prospective follow-up study. Am J Epidemiol 2011;174(9):1017-27.

24. Wise LA, Adams-Campbell LL, Palmer JR, et al. Leisure time physical activity in relation to depressive symptoms in the Black Women's Health Study. Ann Behav Med 2006;32(1):68-76.

25. Smith TL, Masaki KH, Fong K, et al. Effect of walking distance on 8-year incident depressive symptoms in elderly men with and without chronic disease: the HonoluluAsia Aging Study. J Am Geriatr Soc 2010;58(8):1447-52.

26. Cooney GM, Dwan K, Greig CA, et al. Exercise for depression. Cochrane Database Syst Rev 2013;9:CD004366.

27. Rosenbaum S, Vancampfort D, Tiedemann A, et al. Among Inpatients, Posttraumatic Stress Disorder Symptom Severity Is Negatively Associated With Time Spent Walking. Journal of Nervous and Mental Disease 2016;204(1):15-19.

28. Petrovic D, Perovic M, Lazovic B, et al. Association between walking, dysphoric mood and anxiety in late pregnancy: A cross-sectional study. Psychiatry Research 2016;246:360-63.

29. Vallance JK, Eurich D, Lavallee C, et al. Daily Pedometer Steps Among Older Men: Associations With Health-Related Quality of Life and Psychosocial Health. American Journal of Health Promotion 2013;27(5):294-98.

30. Heesch KC, van Uffelen JG, van Gellecum YR, et al. Dose-response relationships between physical activity, walking and health-related quality of life in mid-age and older women. J Epidemiol Community Health 2012;66(8):670-7.

31. Merom $D$, Phongsavan $P$, Wagner $R$, et al. Promoting walking as an adjunct intervention to group cognitive behavioral therapy for an anxiety disorders - A pilot group randomized trial. Journal of Anxiety Disorders 2008;22(6):959-68.

32. Asztalos M, De Bourdeaudhuij I, Cardon G. The relationship between physical activity and mental health varies across activity intensity levels and dimensions of mental health among women and men. Public Health Nutrition 2010;13(8):1207-14.

33. Abedi $P$, Nikkhah $P$, Najar $S$. Effect of pedometer-based walking on depression, anxiety and insomnia among postmenopausal women. Climacteric 2015;18(6):841-45.

34. Pelssers J, Delecluse C, Opdenacker J, et al. "Every Step Counts!": Effects of a Structured Walking Intervention in a Community-Based Senior Organization. Journal of Aging and Physical Activity 2013;21(2):167-85.

35. Ekkekakis $P$, Hall EE, VanLanduyt LM, et al. Walking in (affective) circles: Can short walks enhance affect? Journal of Behavioral Medicine 2000;23(3):245-75.

36. Shin Y-K, Kim DJ, Jung-Choi K, et al. Differences of psychological effects between meditative and athletic walking in a forest and gymnasium. Scandinavian Journal of Forest Research 2013;28(1):64-72.

37. Jin P. Efficacy of Tai Chi, brisk walking, meditation, and reading in reducing mental and emotional stress. J Psychosom Res 1992;36(4):361-70.

38. Streeter CC, Whitfield TH, Owen L, et al. Effects of Yoga Versus Walking on Mood, Anxiety, and Brain GABA Levels: A Randomized Controlled MRS Study. Journal of Alternative and Complementary Medicine 2010;16(11):1145-52.

39. Murphy $M$, Nevill A, Neville $C$, et al. Accumulating brisk walking for fitness, cardiovascular risk, and psychological health. Medicine and science in sports and exercise 2002;34(9):1468-74.

40. Niedermeier $M$, Einwanger $J$, Hartl $A$, et al. Affective responses in mountain hiking-A randomized crossover trial focusing on differences between indoor and outdoor activity. PloS ONE 2017;12(5):e0177719.

41. Hickmann SA, Lee RE, Sallis JF, et al. The association of physical activity change with self-esteem in ethnic minority women: a prospective analysis. Journal of Gender, Culture, and Health 1999;4(4):281-92. 
42. Bergland A, Thorsen K, Loland NW. The relationship between coping, self-esteem and health on outdoor walking ability among older adults in Norway. Ageing \& Society 2010;30(6):949-63.

43. Kovačević Ž, Štefan L, Sporiš G, et al. Differences in Psychological Characteristics Between Different Physical Active Female Students. Sport Science 2015;8(Suppl 1):41-41.

44. Crust L, Henderson $H$, Middleton $G$. The acute effects of urban green and countryside walking on psychological health: a field-based study of green exercise. International Journal of Sport Psychology 2013;44(2):160-77.

45. Anderson AG, Murphy MH, Murtagh E, et al. An 8-week randomized controlled trial on the effects of brisk walking, and brisk walking with abdominal electrical muscle stimulation on anthropometric, body composition, and self-perception measures in sedentary adult women. Psychology of Sport and Exercise 2006;7(5):437-51.

46. Brown DR, Wang Y, Ward A, et al. Chronic psychological effects of exercise and exercise plus cognitive strategies. Medicine \& Science in Sports \& Exercise 1995.

47. Gothe NP, Mullen SP, Wojcicki TR, et al. Trajectories of change in self-esteem in older adults: exercise intervention effects. J Behav Med 2011;34(4):298-306.

48. Elavsky S, McAuley E. Exercise and self-esteem in menopausal women: a randomized controlled trial involving walking and yoga. American journal of health promotion : AJHP 2007;22(2):83-92.

49. Palmer LK. Effects of a walking program on attributional style, depression, and selfesteem in women. Perceptual and Motor skills 1995;81(3):891-98.

50. McAuley E, Blissmer B, Katula J, et al. Physical activity, self-esteem, and self-efficacy relationships in older adults: a randomized controlled trial. Annals of Behavioral Medicine 2000;22(2):131-39.

51. Fox KR. The effects of exercise on self-perceptions and self-esteem. Physical Activity and Psychological Well-being 2000;13:81-118.

52. Kuriyama S, Nakaya N, Ohmori-Matsuda K, et al. Factors associated with psychological distress in a community-dwelling Japanese population: the Ohsaki Cohort 2006 Study. J Epidemiol 2009;19(6):294-302.

53. Teut M, Roesner E, Ortiz $M$, et al. Mindful walking in psychologically distressed individuals: A randomized controlled trial. Evidence-Based Complementary and Alternative Medicine 2013;2013.

54. Toda M, Den R, Hasegawa-Ohira M, et al. Effects of woodland walking on salivary stress markers cortisol and chromogranin A. Complement Ther Med 2013;21(1):29-34.

55. Matzer F, Nagele $\mathrm{E}$, Lerch $\mathrm{N}$, et al. Combining walking and relaxation for stress reduction-A randomized cross-over trial in healthy adults. Stress and Health 2017.

56. Lee AS, Mclnnes RJ, Hughes AR, et al. The effect of the More Active MuMs in Stirling trial on body composition and psychological well-being among postnatal women. Journal of Pregnancy 2016;2016.

57. Cramer SR, Nieman DC, Lee JW. The effects of moderate exercise training on psychological well-being and mood state in women. Journal of Psychosomatic Research 1991;35(4):437-49.

58. Kerse NM, Flicker L, Jolley D, et al. Improving the health behaviours of elderly people: randomised controlled trial of a general practice education programme. BMJ 1999;319(7211):683-7.

59. Sharp $P$, Caperchione $C$. The effects of a pedometer-based intervention on first-year university students: A randomized control trial. Journal of American college health 2016;64(8):630-38.

60. Panahi S, Yunus ASM, Roslan S, et al. Predictors of Psychological Well-Being among Malaysian Graduates. The European Journal of Social and Behavioural Sciences 2016;16:2067-83.

61. Hargreaves EA, Mutrie N, Fleming JD. A Web-Based Intervention to Encourage Walking (StepWise): Pilot Randomized Controlled Trial. JMIR Res Protoc 2016;5(1):e14. 
62. Black SV, Cooper R, Martin KR, et al. Physical activity and mental well-being in a cohort aged 60-64 years. American Journal of Preventive Medicine 2015;49(2):172-80.

63. Martin A, Goryakin Y, Suhrcke M. Does active commuting improve psychological wellbeing? Longitudinal evidence from eighteen waves of the British Household Panel Survey. Preventive Medicine 2014;69:296-303.

64. Morgan AL, Tobar DA, Snyder L. Walking toward a new me: the impact of prescribed walking 10,000 steps/day on physical and psychological well-being. J Phys Act Health, 2010;7(3):299-307.

65. Richards J, Jiang X, Kelly P, et al. Don't worry, be happy: cross-sectional associations between physical activity and happiness in 15 European countries. BMC Public Health 2015;15(1):53.

66. Blacklock RE, Rhodes RE, Brown SG. Relationship between regular walking, physical activity, and health-related quality of life. Journal of Physical Activity and Health 2007;4(2):138-52.

67. McAuley E, Blissmer B, Marquez DX, et al. Social relations, physical activity, and wellbeing in older adults. Prev Med 2000;31(5):608-17.

68. Morgan K, Bath PA. Customary physical activity and psychological wellbeing: a longitudinal study. Age Ageing 1998;27 Suppl 3(suppl_3):35-40.

69. Chng S, White M, Abraham C, et al. Commuting and wellbeing in London: The roles of commute mode and local public transport connectivity. Prev Med 2016;88:182-8.

70. Ku P-W, Fox KR, Chen L-J. Leisure-time physical activity, sedentary behaviors and subjective well-being in older adults: An eight-year longitudinal research. Social Indicators Research 2016;127(3):1349-61.

71. Marselle MR, Irvine KN, Lorenzo-Arribas A, et al. Moving beyond green: exploring the relationship of environment type and indicators of perceived environmental quality on emotional well-being following group walks. Int $\mathrm{J}$ Environ Res Public Health 2014;12(1):106-30.

72. Marselle MR, Irvine KN, Lorenzo-Arribas A, et al. Does perceived restorativeness mediate the effects of perceived biodiversity and perceived naturalness on emotional well-being following group walks in nature? Journal of Environmental Psychology 2016;46:217-32.

73. Focht BC. Brief walks in outdoor and laboratory environments: effects on affective responses, enjoyment, and intentions to walk for exercise. Res $Q$ Exerc Sport 2009;80(3):611-20.

74. Hegberg NJ, Tone EB. Physical activity and stress resilience: Considering those at-risk for developing mental health problems. Mental Health and Physical Activity 2015;8(Supplement C):1-7.

75. Childs $\mathrm{E}$, de Wit $\mathrm{H}$. Regular exercise is associated with emotional resilience to acute stress in healthy adults. Frontiers in Physiology 2014;5:161.

76. Hunter R, Ball K, Sarmiento O. Socially awkward: How can we better promote walking as a social behaviour? . British Journal of Sports Medicine 2018.

77. Van Cauwenberg J, De Donder L, Clarys P, et al. Relationships between the perceived neighborhood social environment and walking for transportation among older adults. Social Science \& Medicine 2014;104:23-30.

78. Maki Y, Ura C, Yamaguchi T, et al. Effects of intervention using a community-based walking program for prevention of mental decline: A randomized controlled trial. Journal of the American Geriatrics Society 2012;60(3):505-10.

79. Watson N, Milat AJ, Thomas M, et al. The feasibility and effectiveness of pram walking groups for postpartum women in western Sydney. Health Promotion Journal of Australia 2005;16(2):93-99.

80. Mutrie N, Doolin O, Fitzsimons CF, et al. Increasing older adults' walking through primary care: results of a pilot randomized controlled trial. Family Practice 2012;29(6):633-42.

81. McNeill LH, Kreuter MW, Subramanian SV. Social environment and physical activity: a review of concepts and evidence. Soc Sci Med 2006;63(4):1011-22. 
82. Gatersleben B, Andrews M. When walking in nature is not restorative-The role of prospect and refuge. Health \& Place 2013;20:91-101.

83. Marselle MR, Irvine KN, Warber SL. Walking for well-being: are group walks in certain types of natural environments better for well-being than group walks in urban environments? International Journal of Environmental Research and Public Health 2013;10(11):5603-28.

84. Martens D, Gutscher H, Bauer N. Walking in "wild" and "tended" urban forests: The impact on psychological well-being. Journal of Environmental Psychology 2011;31(1):36-44.

85. Song $C$, Joung $D$, Ikei $H$, et al. Physiological and psychological effects of walking on young males in urban parks in winter. J Physiol Anthropol 2013;32(1):18.

86. Morita E, Fukuda S, Nagano J, et al. Psychological effects of forest environments on healthy adults: Shinrin-yoku (forest-air bathing, walking) as a possible method of stress reduction. Public Health 2007;121(1):54-63.

87. Tyrväinen $L$, Ojala $A$, Korpela $K$, et al. The influence of urban green environments on stress relief measures: A field experiment. Journal of Environmental Psychology 2014;38:1-9.

88. Pretty J, Peacock J, Hine R, et al. Green exercise in the UK countryside: Effects on health and psychological well-being, and implications for policy and planning. Journal of Environmental Planning and Management 2007;50(2):211-31.

89. Thompson Coon J, Boddy K, Stein K, et al. Does participating in physical activity in outdoor natural environments have a greater effect on physical and mental wellbeing than physical activity indoors? A systematic review. Environmental Science \& Technology 2011;45(5):1761-72.

90. Bowler DE, Buyung-Ali LM, Knight TM, et al. A systematic review of evidence for the added benefits to health of exposure to natural environments. BMC public health 2010;10(1):456.

91. Lubans D, Richards J, Hillman C, et al. Physical activity for cognitive and mental health in youth: A systematic review of mechanisms. Pediatrics 2016:e20161642. 